\title{
A competitive approach for the reduction of unsaturated compounds based on fungal ene-reductases
}

\author{
Romagnolo $A^{1}$, Spina $F^{1}$, Risso $S^{1}$, Brenna $E^{2}$, Crotti $M^{2}$ and Varese GC $^{\mathbf{1}^{*}}$ \\ ${ }^{1}$ Department of Life Science and Systems Biology, University of Torino, 10125 Torino, Italy \\ ${ }^{2}$ Department of Chemistry, Materials and Chemical Engineering, Polytechnic of Milano, 20131 Milano, Italy
}

Romagnolo A, Spina F, Risso S, Brenna E, Crotti M, Varese GC 2016 - A competitive approach for the reduction of unsaturated compounds based on fungal ene-reductases. Mycosphere 7(10), 1588-1599, Doi 10.5943/mycosphere/si/3b/10

\begin{abstract}
The aim of this work was to select potential biocatalysts for the reduction of unsaturated compounds. The ability of Gliomastix masseei, Mucor circinelloides, Mucor plumbeus, Penicillium citrinum and Syncephalastrum racemosum to convert structurally diverse substrates was tested, also considering the role of substituents linked to the $\mathrm{C}=\mathrm{C}$ bond on the process efficiency. All the tested fungi expressed ene-reductase activity when tested with several types of compounds; the ketone derivative was the best substrate, followed by the nitroalkene and the unsaturated aldehyde, whereas the ester was the most recalcitrant to bioreduction.

The results highlighted the potential of Mucor circinelloides MUT 44 and Mucor plumbeus MUT 2769 as versatile whole-cell systems; fast and efficient reduction was obtained using these biocatalysts for most of the compounds. Comparative analysis of the substrate spectrum was performed for three Mucor circinelloides strains, and reaction rates and timings were shown to vary, indicating a strong physiological diversity of ene-reductase activity at the intraspecific level.
\end{abstract}

Key words - asymmetric bioreduction - filamentous fungi - Mucor circinelloides

\section{Introduction}

In the last decade, biocatalysis has been established as a viable alternative to traditional chemical synthesis, combining economic, technological and environmental sustainability. Microorganisms and their enzymes usually need mild reaction conditions, low energetic consumption and minimal use of chemicals (Torres et al. 2003). Therefore, bio-based systems are perfect candidates to be integrated with chemical-manufacturing chains, for sustainable production of existing and novel products (Liese et al. 2006).

The reduction of the $\mathrm{C}=\mathrm{C}$ bond of unsaturated compounds is a key reaction in organic synthesis and is particularly required for producing pharmaceuticals, flavored substances and biologically active compounds (Stueckler et al. 2010, Toogood \& Scrutton 2014, Zagozda \& Plenkiewicz 2006, Williams et al. 2004). To date, industries have promoted this reaction by using metal-based catalysts and renewable resources (Gao et al. 2012). In the past, many reports have highlighted the involvement of microorganisms in the reduction of $\mathrm{C}=\mathrm{C}$ double bonds, identifying the major responsible enzymes. Ene-reductases (ERs) are flavin-dependent oxidoreductases 
belonging to the family of Old Yellow Enzymes (OYE) (E.C. 1.6.99.1) capable of acting on $\mathrm{C}=\mathrm{C}$ double bonds conjugated with electron-withdrawing groups (EWG) in the presence of $\mathrm{NAD}(\mathrm{P}) \mathrm{H}$ as a cofactor (Gatti et al. 2013). Their enrollment in the modern industrial scenario also arises from the ability to produce chiral molecules with high stereoselectivity.

ERs were first discovered in 1933 in Saccharomyces pastorianus (Warburg et al. 1993) and over the years have been described in yeasts, bacteria, plants, animals and some filamentous fungi (Stuermer et al. 2007). Although their physiological role remains largely unknown (Williams \& Bruce 2002), some reports have demonstrated that they are involved in detoxification responses by bacteria (Fitzpatrick et al. 2003) and ergot alkaloid synthesis (Chilton et al. 2014). ERs have been successfully used to reduce several alkenes for research and industrial purposes (Huang et al. 2014, Toogood \& Scrutton 2014).

In recent years, many researchers have focused their attention on new potential biocatalysts within the fungal kingdom. Fungi are robust in harsh operative conditions and their physiological versatility is often an indication of a heterogeneous and highly efficient enzymatic pattern (Colwell 2002). Several studies have shown fungal enantioselective reduction of several unsaturated compounds, e.g. ketones to their secondary alcohols (Carballeira et al. 2004, Zagozda \& Plenkiewicz 2006).

Identifying promising sources of ERs can be achieved by genome mining of databases in the search for targeted sequences. Although OYE genes of $S$. pastorianus may be used as reference constructs, the scarce availability of complete fungal genomes strongly limits this approach (Toogood \& Scrutton 2014). On the other hand, a whole-cell system is a good strategy to screen the activity of ERs among fungi. The use of fungal biomass can also overcome some drawbacks commonly associated with purified enzymes; ERs require regeneration of the cofactor and are often only one step of a multi-enzyme cascade procedure (Toogood \& Scrutton 2014). Whole cells instead represent complete biocatalysts, which can express several enzymes and thus also provide the required cofactors.

In addition, the biocatalytic potential of fungi is often species- and strain-dependent, making it necessary to increase the range of the studied microorganisms. For instance, three fungi have been assessed for the reduction of unsaturated ketones, and have shown great catalytic variability, so that Mortierella isabellina and Geotrichum candidum reduced the $\mathrm{C}=\mathrm{O}$ bond, generating the corresponding alcohol with high enantiomeric excess (94-99\%), whereas Rhodotorula rubra was only active towards the $\mathrm{C}=\mathrm{C}$ double bond with moderate enantioselectivity (Zagozda \& Plenkiewicz 2006). Gongronella butleri, Schizosaccharomyces octosporus and Diplogelasinospora grovesii reduced carvones to dihydrocarvones by the combined action of ERs and alcohol dehydrogenases, but the reaction profile and the secondary products widely varied (Carballeira et al. 2004).

The present study is based on a previous screening carried out by Romagnolo and collaborators (2015). Most of the 28 tested filamentous fungi belonging to different taxonomical groups were able to reduce the double bond of ketone, nitro-derivative and aldehyde compounds. The main aim of this work was to investigate the versatility of the expressed ER activity by using model and non-conventional substrates (i.e. difficult to convert by purified OYEs from yeasts) and the variability among fungi.

\section{Materials \& Methods}

\section{Fungal strains}

The filamentous fungi used are preserved at the Mycotheca Universitatis Taurinensis (MUT, Department of Life Sciences and Systems Biology, University of Turin). A first screening included two ascomycetes and three zygomycetes, while the intraspecific variability was assessed among Mucor circinelloides strains (Table 1). 
Table 1 Species, MUT identification number and isolation site.

\begin{tabular}{lll}
\hline Species & MUT & Isolation site \\
\hline Gliomastix masseei (Sacc. \& Trotter) Matsush. & 4855 & Flabelia petiolata \\
Mucor circinelloides Tiegh. & 44 & unknown \\
Mucor circinelloides Tiegh. & 724 & unknown \\
Mucor circinelloides Tiegh. & 2223 & air from a compost plant \\
Mucor plumbeus Bonord. & 2769 & air \\
Penicillium citrinum Thom & 4862 & Flabelia petiolata \\
Syncephalastrum racemosum Cohn & 2770 & air \\
\hline
\end{tabular}

Scheme 1 - Structure of conventional and non-conventional substrates.

\section{a) conventional substrates}<smiles>O=C1C=CCCC1</smiles>

$\mathrm{CE}$<smiles>C/C(C=O)=C\c1ccccc1</smiles>

MCA<smiles>C/C(=C\c1ccccc1)[N+](=O)[O-]</smiles>

MNS<smiles>COC(=O)/C=C/c1ccccc1</smiles>

MCI

b) non-conventional substrates<smiles>C/C(=C\C#N)c1ccc([N+](=O)[O-])cc1</smiles><smiles>COC(=O)C=C(C#N)c1ccccc1</smiles>

4<smiles>C/C(=C\C#N)c1ccccn1</smiles><smiles>COC(C)=CC(C#N)c1ccc(Cl)cc1</smiles>

5<smiles>C/C=C(\C#N)c1ccccc1</smiles><smiles>CC(=O)C1=CC(C)(C)CCC1</smiles>

6

\section{Substrates}

Cyclohexenone (CE), $\alpha$-methylcinnamaldehyde (MCA) and methyl cinnamate (MCI) were purchased from Sigma-Aldrich (Italy). (E)- $\alpha$-methylnitrostyrene (MNS) was synthesized according to the literature (Kawai et al. 2001) (Scheme 1).

(E)-3-(4-nitrophenyl)but-2-enenitrile (1), (E)-3-(pyridin-2-yl)but-2-enenitrile (2), (Z)-2phenylbut-2-enenitrile (3), (Z)-methyl 3-cyano-3-phenylacrylate (4), and (Z)-methyl 3-cyano-3-(4chlorophenyl)acrylate (5) were prepared according to the literature (Brenna et al 2015a, Knowles \& Cloke 1932, Yan et al. 2015, Yu et al. 2014), while 1-(3,3-Dimethylcyclohex-1-en-1-yl)ethanone (6) was a kind gift from Dr. Philip Kraft (Givaudan Scheiwz AG) (Scheme 1).

Stock solutions $(500 \mathrm{mM})$ were prepared by dissolving each substrate in dimethyl sulfoxide (DMSO). 


\section{Biotransformation experiment}

Fungal strains were pre-grown in Petri dishes containing malt extract agar (MEA: $20 \mathrm{~g} / \mathrm{l}$ glucose, $20 \mathrm{~g} / \mathrm{l}$ malt extract, $20 \mathrm{~g} / \mathrm{l}$ agar, $2 \mathrm{~g} / \mathrm{l}$ peptone). For liquid inoculation a conidia suspension was prepared (final concentration of $1 \times 10^{6}$ conidia in each flask) and inoculated in $100 \mathrm{ml}$ flasks containing $40 \mathrm{ml}$ of malt extract liquid medium (MEA without agar). Flasks were maintained at 25 ${ }^{\circ} \mathrm{C}$ in agitation (110 rpm). After 2 days, substrates were added separately (5 mM final concentration). Three flasks for each fungus were sacrificed to measure the initial biomass and $\mathrm{pH}$. For each substrate, three other biological replicates were set up. The experiment ran for 7 days and $1 \mathrm{ml}$ of cultural broth was collected daily for chemical analysis.

\section{Gas chromatography-mass spectrometry (GC/MS) analysis}

Samples were extracted by two-phase separation using $0.4 \mathrm{ml}$ of methyl t-butyl ether (MTBE) as a solvent. The organic phases were dried over anhydrous $\mathrm{Na}_{2} \mathrm{SO}_{4}$ and analyzed by means of GC/MS. GC/MS analyses were performed using an Agilent HP 6890 gas chromatograph equipped with a 5973 mass detector and an HP-5-MS column $(30 \mathrm{~m} \times 0.25 \mathrm{~mm} \times 0.25 \mu \mathrm{m}$, Agilent $)$, employing the following temperature program: $60{ }^{\circ} \mathrm{C}(1 \mathrm{~min}) / 6{ }^{\circ} \mathrm{C} \mathrm{min}^{-1} / 150{ }^{\circ} \mathrm{C}(1$ $\min ) / 12{ }^{\circ} \mathrm{C} \min ^{-1} / 280{ }^{\circ} \mathrm{C}(5 \mathrm{~min})$.

GC retention times of $\mathrm{CE}, \mathrm{MCA}, \mathrm{MNS}$, and $\mathrm{MCI}$ and of the corresponding reduced compounds have been previously described (Brenna et al. 2015b, Romagnolo et al. 2015). GC retention times of compounds 1-3 and $\mathbf{6}$ and of the reduced products obtained from $\mathbf{3}$ and $\mathbf{6}$ are the following: $123.35 \mathrm{~min}, \mathbf{2} 16.50 \mathrm{~min}, \mathbf{3} 14.32 \mathrm{~min}$, red-3 $12.87 \mathrm{~min}, \mathbf{6} 11.04 \mathrm{~min}$, red-6 $10.35 \mathrm{~min}$, GC retention times of compounds 4-5 and of the corresponding reduced products have been previously described (Brenna et al. 2015b).

\section{pH and biomass dry weight}

$\mathrm{pH}$ was measured after 2 days of pre-growth and at the end of the experiment.

Biomass dry weight was calculated by separating the biomass from the liquid by filtration, which was further dried at $60{ }^{\circ} \mathrm{C}$ for $24 \mathrm{~h}$.

\section{Results}

\section{Reduction of conventional substrates}

All the tested strains reduced at least three out of the four model substrates (Table 2). Although the timing of the reaction varied between the different fungi, a common reaction profile for cyclohexenone (CE) was observed. Independently of the fungus, due to the presence of ERs, chromatographic analysis initially detected a saturated ketone (cyclohexanone) that was further transformed by an alcohol dehydrogenase into the corresponding saturated alcohol (cyclohexanol) (Scheme 2). All the strains catalyzed a complete reduction; the two strains belonging to Mucor genera were the most rapid, reducing $100 \%$ of CE within the first 2 days of treatment.

With the exception of $S$. racemosum MUT 2770, a good level of conversion of $(E)$ - $\alpha-$ methylnitrostyrene (MNS) into (2-nitropropyl)benzene (Scheme 2) was observed in all the strains. P. citrinum MUT 4862 obtained the highest yields (99\%), but the two Mucor strains were the fastest (79-86\% in 2 days).

Fungi reduced the carbonyl group (CHO) of $\alpha$-methylcinnamaldehyde (MCA), and partially reduced the $\mathrm{C}=\mathrm{C}$ double bond, ultimately leading to a mixture of unsaturated and saturated alcohols (Scheme 2). The complete reduction of MCA, with a final product of 2-methyl-3-phenylpropan-1ol, was achieved by M. circinelloides MUT 44 and M. plumbeus MUT 2769.

The transformation of methyl cinnamate (MCI) led exclusively to the formation of the saturated alcohol 3-phenylpropanol, due to the combined activity of ERs and other enzymes (i.e. esterases for ester hydrolysis, carboxylic acid reductases for the reduction of the carboxylic acid to aldehyde, alcohol dehydrogenases for the conversion of the aldehyde into primary alcohol) 
(Scheme 2). M. circinelloides MUT 44 (100\%) and S. racemosum MUT 2770 (99\%) were the only strains capable of extensively reducing MCI.

Scheme 2 - Reaction paths of conventional substrates.<smiles>O=C1C=CCCC1</smiles>

CE<smiles>O=C1CCCCC1</smiles>

cyclohexanone<smiles>OC1CCCCC1</smiles>

cyclohexanol<smiles>C/C(=C\c1ccccc1)[N+](=O)[O-]</smiles>

MNS<smiles>CC(Cc1ccccc1)[N+](=O)[O-]</smiles>

(2-nitropropyl)benzene<smiles>CCC=O</smiles>

$\mathrm{MCA}$<smiles>C/C(=C\c1ccccc1)CO</smiles>

(E)-2-methyl-3phenylprop-2-en-1-ol<smiles>OCCCc1ccccc1</smiles>

3-phenylpropan-1-ol

Table 2 Maximum percentage of $\mathrm{C}=\mathrm{C}$ double bond reduction of conventional ER substrates; timing is reported in brackets.

\begin{tabular}{cccccc}
\hline & G. masseei & M. circinelloides & M. plumbeus & P. citrinum & S. racemosum \\
\hline CE & $100(7 \mathrm{~d})$ & $100(2 \mathrm{~d})$ & $100(2 \mathrm{~d})$ & $100(7 \mathrm{~d})$ & $100(7 \mathrm{~d})$ \\
MNS & $61(7 \mathrm{~d})$ & $86(2 \mathrm{~d})$ & $79(2 \mathrm{~d})$ & $99(7 \mathrm{~d})$ & $16(7 \mathrm{~d})$ \\
MCA & $51(7 \mathrm{~d})$ & $99(2 \mathrm{~d})$ & $98(7 \mathrm{~d})$ & $3(7 \mathrm{~d})$ & - \\
MCI & - & $100(7 \mathrm{~d})$ & $13(7 \mathrm{~d})$ & - & $99(7 \mathrm{~d})$ \\
\hline
\end{tabular}

\section{Reduction of non-conventional substrates}

To further explore the profile of the fungal ER activity, other unsaturated compounds were used. The substrates were chosen because they were poorly converted by purified wild type OYE13 from yeasts (data not shown). Four out of the five fungi promoted reduction of the $\mathrm{C}=\mathrm{C}$ double bond of at least one of the analyzed substrates (Table 3) (Scheme 3). M. plumbeus MUT 2769 and M. circinelloides MUT 44 were the most versatile fungi, being able to transform four and three substrates, respectively. G. masseei MUT 4855 did not reduce any substrate.

The recalcitrance of the compounds for ER-mediated reduction was highlighted by the scarce or absent conversion observed in most cases (Table 3). Substrates $\mathbf{1}$ and $\mathbf{2}$ were unaffected by all the fungi. Moderate transformation (20-30\%) of substrates $\mathbf{3}$ and $\mathbf{4}$ into the corresponding reduced compounds was obtained by the two fungi belonging to the Mucor genus.

Substrate 5 was only reduced by S. racemosum MUT 2770 and M. plumbeus MUT 2769, the latter with high yields $(86 \%)$. 
Substrate 6 was converted by three fungi, but only $M$. circinelloides MUT 44 reached considerable process yields $(69 \%)$.

Scheme 3 - Reaction paths of non-conventional substrates.<smiles>CC=C(C)c1ccccc1</smiles>

3<smiles>CCC(C#N)c1ccccc1</smiles>

red-3<smiles>CC(C)(C)CC(=O)CC(C#N)c1ccccc1</smiles><smiles>CC(=O)CC(C#N)c1ccc(Cl)cc1</smiles><smiles>CC(=O)C1=CC(C)(C)CCC1</smiles><smiles>CC(=O)C1CCCC(C)(C)C1</smiles>

red-6

Table 3 Maximum percentage of $\mathrm{C}=\mathrm{C}$ double bond reduction of non-conventional ER substrates; the timing is reported in brackets.

\begin{tabular}{llllll}
\hline & G. masseei & M. circinelloides & M. plumbeus & P. citrinum & S. racemosum \\
\hline $\mathbf{1}$ & - & - & - & - & - \\
$\mathbf{2}$ & - & - & - & - & - \\
$\mathbf{3}$ & - & $21(7 \mathrm{~d})$ & $11(7 \mathrm{~d})$ & - & - \\
$\mathbf{4}$ & - & $5(7 \mathrm{~d})$ & $29(2 \mathrm{~d})$ & - & - \\
$\mathbf{5}$ & - & - & $86(2 \mathrm{~d})$ & - & $53(2 \mathrm{~d})$ \\
$\mathbf{6}$ & - & $69(7 \mathrm{~d})$ & $7(7 \mathrm{~d})$ & $10(7 \mathrm{~d})$ & - \\
\hline
\end{tabular}

\section{Evaluation of the intraspecific variability}

M. circinelloides MUT 44 was capable of reducing seven model and non-conventional compounds, five of which by more than $60 \%$. Importantly, it was active toward compounds (e.g. MCI and substrate 6) that were poor substrates for the other tested fungi. Since little is known about the presence of ERs within strains of the same species, three strains of $M$. circinelloides were used to treat the model compounds, since they were representative of different chemical classes.

M. circinelloides MUT 44 and MUT 724 converted all the substrates, showing different process yields and substrate spectrums; MUT 44 was more active toward MCI, while MUT 724 toward MCA and MNS. Conversely, the reduction potential of M. circinelloides MUT 2223 was 
very weak, being partially active (12\%) toward CE only (Table 4). Biotransformation always occurred within the first 2 days and no significant variation could be observed afterwards.

Table 4 Maximum percentage of $\mathrm{C}=\mathrm{C}$ double bond reduction of three $M$. circinelloides strains; the timing is reported in brackets.

\begin{tabular}{llll}
\hline & MUT 44 & MUT 724 & MUT 2223 \\
\hline CE & $100(2 \mathrm{~d})$ & $100(2 \mathrm{~d})$ & $12(2 \mathrm{~d})$ \\
MCA & $60(2 \mathrm{~d})$ & $100(2 \mathrm{~d})$ & - \\
MNS & $75(2 \mathrm{~d})$ & $95(2 \mathrm{~d})$ & - \\
MCI & $78(2 \mathrm{~d})$ & $43(2 \mathrm{~d})$ & - \\
\hline
\end{tabular}

\section{Discussion}

Bioreduction of $\mathrm{C}=\mathrm{C}$ double bonds is an attractive solution for "green" production of building block compounds, but the number of biocatalysts (microorganisms and enzymes) that have strong catalytic potential is still limited. Although OYEs of yeast and bacteria have already been investigated (Stuermer et al. 2007, Toogood \& Scrutton 2014), there is still a need for new biobased systems capable of performing stereoselective reductions. This study was based on a wider screening of fungal ERs (Romagnolo et al. 2015), from which five filamentous fungi were selected. Results indicated that a strong ER activity was expressed by all the species, but not homogenously diffused between them. Bioreduction rates and timings often resulted as being strain-dependent, underlining the importance of choosing the most suitable biocatalyst.

G. masseei MUT 4855, M. circinelloides MUT 44, M. plumbeus MUT 2769, P. citrinum MUT 4862 and S. racemosum MUT 2770 all displayed a versatile ER activity, being capable of reducing unsaturated compounds belonging to at least three different chemical classes.

Although many $\alpha, \beta$-unsaturated compounds have been tested, the used compounds rarely coincided (Toogood \& Scrutton 2014). Moreover, the majority of studies have investigated the reduction of a few molecules belonging to a single chemical class (i.e. ketones), giving little information about the versatility of the microorganisms (Goretti et al. 2009, Stueckler et al. 2010). Therefore, the absence of model substrates creates concerns about the possibility of comparing the data with the literature.

In addition, non-activated $\mathrm{C}=\mathrm{C}$ double bonds do not undergo reduction and the presence of an EWG on the alkene is required (Toogood \& Scrutton 2014). A large variety of activating groups (e.g. aldehyde, ketone, imide, nitro, carboxylic acid and ester) have been assessed and have been shown to correlate with the conversion yields of yeast OYEs and bacterial and plant homologues: reaction rates and enantioselectivity varied according to the substrate and the isoform (Hall et al. 2008a, Hall et al. 2008b, Reß et al. 2015). To the best of the authors' knowledge, different substrates including ketones, nitro derivatives, aldehydes and esters have never been considered for filamentous fungi. These data may indeed help to widen the knowledge about the role of EWGs in reactions catalyzed by OYE homologues among ascomycetes and zygomycetes. In particular, carboxylic acids, nitriles and esters are well-known to be weak EWGs, limiting the reduction efficiency towards these substrates (Stuermer et al. 2007). This evidence fit well with the results of this study; the conversion of four model substrates followed the profile, ketone (cyclohexanone, CE) > nitroalkene $(\alpha$-methylnitrostyrene, MNS) > aldehyde $(\alpha$-methylcinnamaldehyde, MCA) > ester (methyl cinnamate, MCI).

Fungal-mediated biocatalysis has been found to be very efficient in the presence of a ketone group; even highly branched and substituted unsaturated ketones were good substrates for fungi, i.e. the ascomycetes $P$. citrinum, G. candidum and Diplogelasinospora grovesii, the zygomycetes M. isabellina and the basidiomycete Pleurotus ostreatus (Aquino et al. 2012, Ferreira et al. 2015, Quezada et al. 2012, Skrobiszewski et al. 2012, Zagozda \& Plenkiewicz 2006). Of the studied fungi, $P$. citrinum has been previously found to be capable of producing ERs (Aquino et al. 2012, Ferreira et al. 2015); the conversion of CE observed by P. citrinum MUT 4862 is therefore not surprising. In the present study, all the different fungal strains achieved a complete conversion of 
CE within 2 days. Some previous studies have considered CE and its analogue, allowing comparison of the obtained data with previous evidence; filamentous fungi resulted as being highly competitive with other organisms (yeasts, bacteria and plants) and their enzymes. For instance, among 146 yeasts, only $11 \%$ reduced an unsaturated simple ketone (e.g. carvone), but the conversion was completed only by Pichia amylophila and S. naganishii (Goretti et al. 2009). OYE1 of Saccharomyces carlsbengensis carried out almost complete bioconversions of $\mathrm{CE}$ and its derivatives, whereas OYE2 and OYE3 of S. cerevisiae were less efficient, i.e. $75 \%$ and $7 \%$ of CE reduction, respectively (Stueckler et al. 2010). Controversial results are instead associated with bacterial and plant enzymes (Stueckler et al. 2010); of the five tested bacterial OYE homologues and the two enzymes from tomato, only two of them were capable of reducing the $\mathrm{C}=\mathrm{C}$ double bond of CE, namely YqjM from Bacillus subtilis and Zymomonas NCR-reductase converted 85\% and 7\%, respectively (Stueckler et al. 2010).

Unsaturated aldehydes are usually good substrates for ERs, as demonstrated by the high reactivity of ERs from the yeast Kluyveromyces lactis and the bacteria Pseudomonas putida and Yersinia bercovieri (Chaparro-Riggers et al. 2007). However, contrasting data has also been reported, among 17 bacteria, 20 yeasts and 9 filamentous fungi, only the bacterium Zymomonas mobilis reduced the aldehyde citral (Muller et al. 2006). Considering that only $S$. racemosum MUT 2770 did not react toward MCA, the reduction of aldehydes seemed to be a widespread reaction among filamentous fungi. The highest activity was observed for the two zygomycetes belonging to the Mucor genus. The unique features of the enzymatic pattern of M. plumbeus MUT 2769 were demonstrated by comparing with the literature, where the overall conversion of the aldehyde citral by $M$. plumbeus strain was instead negligible (Hall et al. 2006).

A common reaction profile was observed. The transformation of MCA gave a mixture of unsaturated and saturated alcohols, indicating that a carbonyl reductase had already reduced the aldehyde to the corresponding alcohol. This pathway is in agreement with previous observations with recombinant strains of $S$. cerevisiae (Romano et al. 2014) and filamentous fungi (Romagnolo et al. 2015), indicating the presence of a multi-step enzymatic cascade able to reduce both the carbonyl group and the $\mathrm{C}=\mathrm{C}$ double bond.

Nitroalkene reduction is a very common step in the synthesis of nitroalkanes for pharmaceutical preparation and, so far, it has been performed by bacteria- and yeast-based methods. In the present study, three out of five filamentous fungi achieved percentages of conversion of MNS above $80 \%$, in accordance with previous finding using whole-cell systems based on Saccharomyces cerevisiae, E. coli and Clostridium sporogenes (Fryszkowska et al. 2008, Jovanovic et al. 2014, Kawai et al. 2001). Since both the typology and the position of each substituent has been found to deeply affect the stereoselectivity of bacteria, yeast and plant enzymes (Burda et al. 2013, Fryszkowska et al. 2008, Hall et al. 2008a, Reß et al. 2015), the tested range of analytes should also be extended for filamentous fungi.

As unsaturated esters are usually poorly converted by ERs, the complete reduction of MCI catalyzed by $M$. circinelloides MUT 44 and S. racemosum MUT 2770 stimulates great interest. For instance, among the 23 recombinant ERs tested, only four were active on an ester molecule, with very low (9-11\%) conversion yields (Reß et al. 2015). A putative ER of Clavispora lusitaniae converted only one out of three ester molecules (Ni et al., 2014).

Particular attention was paid to the ability of M. circinelloides MUT 44 and M. plumbeus MUT 2769 to reduce non-conventional substrates, which are usually not reduced by OYEs from bacteria and yeasts (unpublished results). Furthermore, the development of a bio-based technology for cyano-saturated compounds may lead to potentially industrial outcomes, i.e. the production of neurological active compounds, such as non-natural amino acids (Brenna et al. 2013). However, accordingly to previous findings (Liu et al. 2012, Reß et al. 2015), cyano-compounds (substrates 15) showed a poor rate of conversion. Although substrates 1-3 share a similar basic scaffold, the tested fungi were not suitable for the reduction of substrates $\mathbf{1}$ and $\mathbf{2}$, but a moderate transformation of substrate 3 occurred (i.e. $21 \%$ by $M$. circinelloides MUT 44). The absence of substituents on the aromatic ring of substrate 3 probably aided the reduction of the $\mathrm{C}=\mathrm{C}$ bond. 
Fungi were more active toward cyano esters (e.g. substrates 4-5). Similarly, a cyano acid was moderately (e.g. $26 \%$ at maximal) converted by 6 out of 23 ERs, whereas two cyano esters were reduced by most of the enzymes, five of which generated yields of above $50 \%$ (Reß et al. 2015). Ten out of 12 cyano esters were transformed by S. cerevisiae and/or by OYEs (Brenna et al. 2013).

Moreover, substitutions on the aromatic ring often positively or negatively affect enzymatic kinetics, due to their steric hindrance and electronic effects. For instance, even though substrates 4 and $\mathbf{5}$ only differ by a chlorine substitution on the aromatic ring, only $\mathbf{5}$ was extensively reduced. $S$. racemosum MUT 2770 was only active toward substrate 5 (53\%) whereas $M$. circinelloides MUT 44 reduced $86 \%$ and $29 \%$ of $\mathbf{4}$ and $\mathbf{5}$, respectively. The role of halogens must be carefully assessed and it is difficult to make generalizations between chemical classes. For instance, by acting as a secondary EWG, the presence of a halogen may be critical for the reduction of esters. In other cases, being in the $\alpha$ position of the $\mathrm{C}=\mathrm{C}$ double bond, it can promote the reaction (Gatti et al. 2013).

Substrate $\mathbf{6}$ is a commercial product employed as a building block material for the synthesis of fragrances, e.g. musk odorants, which are usually produced via chemical synthesis (Liu et al. 2014, Nacsa et al. 2015). No evidence could be found about its transformation by biological methodologies, thus creating great interest in the bioconversion rates of $M$. circinelloides MUT 44, M. plumbeus MUT 2769 and P. citrinum MUT 4862. Indeed, having reduced 69\% of substrate 6, M. circinelloides MUT 44 should be investigated in further detail to define its potential as a new biocatalyst for fragrance production.

Although intraspecific physiological variability is well-known in the fungal kingdom (Fontaine et al. 2015, Johnson et al. 2012), no studies have investigated the diffusion of ER activity among strains belonging to the same species. In the present study, the intraspecific diversity among three strains of $M$. circinelloides was considerable, and each strain displayed a different substrate profile. M. circinelloides MUT 2223 was barely active only on the ketone, whereas the other two strains were highly versatile, reaching high conversion rates $(>75 \%)$ for three out of four tested compounds. Slight differences were evident according to the EWG: MUT 44 and MUT 724 poorly reduced ketones and esters, respectively.

In conclusion, by evaluating the reduction of ten unsaturated molecules, the great potential of $M$. circinelloides MUT 44 was revealed; it coupled high conversion yields of seven analytes, fast reactions and high versatility, being active towards all the chemical classes tested.

\section{Acknowledgements}

This project was supported by the Fondazione CRT (Torino, Italy). The authors would like to thank the Fondazione San Paolo (Turin, Italy) for their economic support of the PhD program of Alice Romagnolo.

\section{References}

Aquino GLB, Oliveira B, Didonet CCM. 2012 - Biocatalytic reduction of (+)-carvone and (-)carvone in submerged cultures of the fungi Penicillium citrinum and Fusarium oxysporium. Biocatalysis and Biotransformation 30, 455-458.

Brenna E, Cannavale F, Crotti M, Parmeggiani F, Romagnolo A, Spina F, Varese GC. 2015b Biocatalysed reduction of carboxylic acids to primary alcohols in aqueous medium: a novel synthetic capability of the zygomycete fungus Syncephalastrum racemosum. Journal of Molecular Catalysis B: Enzymatic 116, 83-88.

Brenna E, Crotti M, Gatti FG, Monti D, Parmeggiani F, Powell RT, Santangelo S, Stewart JD. 2105 a - Opposite enantioselectivity in the bioreduction of (Z)- $\beta$-aryl- $\beta$-cyanoacrylates mediated by the tryptophan 116 mutants of old yellow enzyme 1: synthetic approach to (R)and (S)- $\beta$-aryl- $\gamma$-lactams. Advanced Synthesis \& Catalysis 357, 1849-1860. 
Brenna E, Gatti FG, Manfredi A, Monti D, Parmeggiani F. 2013 - Old Yellow Enzyme-mediated reduction of $\beta$-cyano- $\alpha, \beta$-unsaturated esters for the synthesis of chiral building blocks: stereochemical analysis of the reaction. Catalysis Science \& Technology 3, 1136-1146.

Burda E, Reß T, Winkler T, Giese C, Kostrov X, Huber T, Hummel W, Gröger H. 2013 - Highly enantioselective reduction of $\alpha$-methylated nitroalkenes. Angewandte Chemie International Edition 52, 9323-9326.

Carballeira JD, Valmaseda M, Alvarez E, Sinisterra Gago JV. 2004 - Gongronella butleri, Schizosaccharomyces octosporus and Diplogelasinospora grovesii: novel microorganisms useful for the stereoselective reduction of ketones. Enzyme and Microbial Technology 34, 611-623.

Chaparro-Riggers JF, Rogers TA, Vazquez-Figuero E, Polizzi KM, Bommarius AS. 2007 Comparison of three enoate reductases and their potential use for biotransformations. Advanced Synthesis \& Catalysis 349, 1521-1531.

Chilton AS, Ellis AL, Lamb AL. 2014 - Structure of an Aspergillus fumigatus old yellow enzyme (EasA) involved in ergot alkaloid biosynthesis. Acta Crystallographica Section F Structural Biology Communications 70, 1328-1332.

Colwell RR. 2002 - Fulfilling the promise of biotechnology. Biotechnology Advances 20, 215228.

Ferreira IM, Meira EB, Rosset IG, Porto ALM. 2015 - Chemoselective biohydrogenation of $\alpha, \beta$ and $\alpha, \beta, \gamma, \delta$-unsaturated ketones by the marine-derived fungus Penicillium citrinum CBMAI1186 in a biphasic system. Journal of Molecular Catalysis B: Enzymatic 115, 59-65.

Fitzpatrick TB, Amrhein N, Macheroux P. 2003 - Characterization of YqjM, an old yellow enzyme homolog from Bacillus subtilis involved in the oxidative stress response. The Journal of Biological Chemistry 278, 19891-19897.

Fontaine K, Hymery N, Lacroix MZ, Puel S, Puel O, Rigalma K, Gaydou V, Cotona E, Mounier J. 2015 - Influence of intraspecific variability and abiotic factors on mycotoxin production in Penicillium roqueforti. International Journal of Food Microbiology 215, 187-193.

Fryszkowska A, Fisher K, Gardiner JM, Stephens GM. 2008 - Highly enantioselective reduction of $\beta, \beta$-disubstituted aromatic nitroalkenes catalyzed by Clostridium sporogenes. The Journal of Organic Chemistry 73, 4295-4298.

Gao X, Ren J, Wu Q, Zhu D. 2012 - Biochemical characterization and substrate profiling of a new NADH-dependent enoate reductases from Lactobacillus casei. Enzyme and Microbial Technology 51, 26-34.

Gatti G, Parmeggiani F, Sacchetti A. 2013 - Synthetic methods for biologically active molecules: exploring the potential of bioreductions, Wiley-VCH Verlag GmbH.

Goretti M, Ponzoni C, Caselli E, Marchigiani E, Cramarossa MR, Turchetti B, Buzzini P, Forti L. 2009 - Biotransformation of electron-poor alkenes by yeasts: asymmetric reduction of (4S)(+)-carvone by yeast enoate reductases. Enzyme and Microbial Technology 45, 463-468.

Hall M, Hauer B, Stuermer R, Kroutil W, Faber K. 2006 - Asymmetric whole-cell bioreduction of an $\alpha, \beta$-unsaturated aldehyde (citral): competing prim-alcohol dehydrogenase and $\mathrm{C}-\mathrm{C}$ lyase activities. Tetrahedron: Asymmetry 17, 3058-3062.

Hall M, Stueckler C, Hauer B, Stuermer R, Friedrich T, Breuer M, Kroutil W, Faber K. 2008a Asymmetric bioreduction of activated $\mathrm{C}=\mathrm{C}$ bonds using Zymomonas mobilis NCR enoate reductase and old yellow enzymes OYE 1-3 from yeasts. European Journal of Organic Chemistry, 1511-1516.

Hall M, Stueckler C, Ehammer H, Pointner E, Oberdorfer G, Gruber K, Hauer B, Stuermer R, Kroutil W, Macheroux P, Faber K. 2008b - Asymmetric bioreduction of C=C bonds using enoate reductases OPR1, OPR3 and YqjM: enzyme-based stereocontrol. Advanced Synthesis \& Catalysis 350, 411-418.

Huang M, Hu H, Ma L, Zhou Q, Yu L, Zeng S. 2014 - Carbon-carbon double bond reductases in nature. Drug Metabolism Reviews 46, 362-378. 
Johnson D, Martin F, Cairney JWG, Anderson IC. 2012 - The importance of individuals: intraspecific diversity of mycorrhizal plants and fungi in ecosystems. New Phytologist 194, 614-628.

Jovanovic P, Jeremic S, Djokic L, Savic V, Radivojevic J, Maslak V, Ivkovic B, Vasiljevic B, Nikodinovic-Runic J. 2014 - Chemoselective biocatalytic reduction of conjugated nitroalkenes: new application for an Escherichia coli BL21(DE3) expression strain. Enzyme and Microbial Technology 60, 16-23.

Kawai Y, Inaba Y, Tokitoh N. 2001 - Asymmetric reduction of nitroalkenes with Baker's yeast. Tetrahedron: Asymmetry 12, 309-318.

Knowles EC, Cloke JB. 1932 - Substituted phenylacetonitriles and derivatives. 1-phenyl-1cyanocyclopropane, alpha-phenyl-gamma-hydroxybutyronitrile, alpha-phenyl-gammachlorobutyronitrile and alpha-phenylcrotononitriles. Journal of the American Chemical Society $2028-2036$.

Liese A, Seelbach K, Wandrey C. 2006 - Industrial Biotransformations. Wiley-VCH Verlag $\mathrm{GmbH}$.

Liu J, Zhang Q, Li P, Qu Z, Sun S, Ma Y, Su D, Zong Y, Zhang J. 2014 - Six-membered silacycle odorants: synthesis and olfactory characterization of $\mathrm{Si}$ analogues of artemone, $\beta$-dynascone, and herbac. European Journal of Inorganic Chemistry 3435-3440.

Liu Y-J, Pei X-O, Lin H, Gai P, Liu Y-C, Wu Z-L. 2012 - Asymmetric bioreduction of activated alkenes by a novel isolate of Achromobacter species producing enoate reductase. Applied Microbiology and Biotechnology 95, 635-645.

Muller A, Hauer B, Rosche B. 2006 - Enzymatic reduction of the $\alpha, \beta$-unsaturated carbon bond in citral. Journal of Molecular Catalysis B: Enzymatic 38, 126-130.

Nacsa ED, Fielder BC, Wetzler SP, Srisuknimit V, Litz JP, Van Vleet MJ, Quach K, Vosburg DA. 2015 - Direct, biomimetic synthesis of (+)-artemone via a stereoselective, organocatalytic cyclization. Synthesis 47, 2599-2602.

Ni Y, Yu H-L, Lin G-Q, Xu J-H. 2014 - An ene reductase from Clavispora lusitaniae for asymmetric reduction of activated alkenes. Enzyme and Microbial Technology 56, 40-45.

Quezada MA, Carballeira JD, Sinisterra JV. 2012 - Diplogelasinospora grovesii IMI 171018 immobilized in polyurethane foam. An efficient biocatalyst for stereoselective reduction of ketones. Bioresource Technology 112, 18-27.

Reß T, Hummel W, Hanlon SP, Iding H, Gröger H. 2015 - The organic-synthetic potential of recombinant ene reductases: substrate-scope evaluation and process optimization. ChemCatChem 7, 1302-1311.

Romagnolo A, Spina F, Brenna E, Crotti M, Parmeggiani F, Varese GC. 2015 - Identification of fungal ene-reductase activity by means of a functional screening. Fungal Biology 119, 487493.

Romano D, Contente ML, Molinari F, Eberini I, Ruvutuso E, Sensi C, Amaretti A, Rossi M, Raimondi S. 2014 - Recombinant S. cerevisiae expressing old yellow enzymes from nonconventional yeasts: an easy system for selective reduction of activated alkenes. Microbial Cell Factories 13, 1-9.

Skrobiszewski A, Ogorek R, Plaskowska E, Gladkowski W. 2013 - Pleurotus ostreatus as a source of enoate reductase. Biocatalysis in Agricoltural Biotechnology 2, 26-31.

Stueckler C, Reiter TC, Baudendistel N, Faber K. 2010 - Nicotinamide-independent asymmetric bioreduction of $\mathrm{C}=\mathrm{C}$-bonds via disproportionation of enones catalyzed by enoate reductases. Tetrahedron 66, 663-667.

Stuermer R, Hauer B, Hall M, Faber K. 2007 - Asymmetric bioreduction of activated C=C bonds using enoate reductases from the old yellow enzyme family. Current Opinion in Chemical Biology 11, 203-213.

Toogood HS, Scrutton NS. 2014 - New developments in 'ene'-reductase catalysed biologica hydrogenations. Current Opinion in Chemical Biology 19, 107-115.

Torres E, Bustos-Jaimes I, Le Borgne S. 2003 - Potential use of oxidative enzymes for the 
detoxification of organic pollutants. Applied Catalysis B: Environmental 46, 1-15.

Warburg O, Christian W. 1933 - Uber das gelbe ferment und seine wirkungen. Biochemische Zeitschrift 266, 377-411.

Williams RE, Bruce NC. 2002 - 'New uses for an old enzyme' - the old yellow enzyme family of flavoenzymes. Microbiology 148, 1607-1614.

Williams RE, Rathbone DA, Scrutton NS, Bruce NC. 2004 - Biotransformation of explosives by the old yellow enzyme family of flavoproteins. Applied and Environmental Microbiology 70, 3566-3574.

Yan Q, Kong D, Li M, Hou G, Zi G. 2015 - Highly efficient Rh-catalyzed asymmetric hydrogenation of $\alpha, \beta$-unsaturated nitriles. Journal of the American Chemical Society 10177 10181.

Yu D, Gensch T, De Azambuja F, Vasquez-Cespedes S, Glorius F. 2014 - Co(III)-catalyzed C-H activation/formal SN-type reactions: selective and efficient cyanation, halogenation, and allylation. Journal of the American Chemical Society 136, 17722-17725.

Zagozda M, Plenkiewicz J. 2006 - Enantioselective reduction of $\alpha, \beta$-unsaturated ketones by Geotrichum candidum, Mortierella isabellina and Rhodotorula rubra yeast. Tetrahedron: Asymmetry 17, 1958-1962. 